\title{
Kinetic and Mechanistic Study of Oxidation of 3-Methyl-2- Butanone by Isoquinolinium Bromochromate
}

\author{
Khushboo Trivedi ${ }^{1 *}$, M. U. Khan ${ }^{1}$, Arvind Prasad Dwivedi ${ }^{2}$ \\ ${ }^{1}$ Department of Chemistry, Govt. Model Science College, Rewa-486001 (M.P.) India \\ ${ }^{2}$ Department of Chemistry, Govt. Sanjay Gandhi Smrati Auto.P.G.College Sidhi, (M.P.) India
}

*Corresponding Author: Khushboo Trivedi, Research Scholar, Govt. Model Science College, Rewa486001 (M.P.) India

\begin{abstract}
The kinetic and mechanistic study of 3-methyl-2-butanone has been explored with isoquinolinium bromochromate $(I Q B C)$ in aqueous acidic acid medium at temperature $308 \mathrm{~K}$. The rate of reactions was found proportional to first power of concentration IQBC and $\mathrm{H}^{+}$ion. The study provides an evidence for per complex formation between oxidant's species and enolic ketone. The rate of oxidation increases with, decreasing dielectric constant of the medium. The effect of salt does not alter the rate of reaction. The added catalysts $\mathrm{CuSO}_{4}$ and $\mathrm{MnSO}_{4}$ bring about the change in rate of oxidation. The study discards the involvement of free radicals based mechanism for stoichiometric ratio 1:1 of the reaction. Several thermodynamic parameters were determined at different temperatures. The mechanism and rate law was proposed accordingly.
\end{abstract}

Keywords: Alter, significance, validity, involvement, assumptions.

\section{INTRODUCTION}

The investigated 3-methyl-2-butanone, is a aliphatic ketone, shows the phenomenon of tautomerism at equilibrium and exhibited a variety of chemical reactions with different oxidizing reagents such as $\mathrm{SeO}_{2}{ }^{[1]}, \mathrm{NBSA}^{2}$, acid-bromate ${ }^{3},\left[\mathrm{Fe}(\mathrm{CN})_{4}\right]^{[3-4]}$ etc. The study of such reaction is of great significance and of interest because of its vast implication in understanding the nature of chemical processes involved.

A variety of compounds containing Cr (IV) ${ }^{[5-8]}$ have stabilised to be versatile reagent, capable of commencing oxidations almost every oxidizing functional group. In this series, Isoquinolinium bromochromate has been used in the kinetics and mechanistic study of 2-alkanones, ${ }^{9}$ protonation of dialkyl acetone dicarboxyxlates ${ }^{\mathbf{1 0}}$ and in bromination of hydroxylated aromatic compounds ${ }^{11}$ etc. The current surve of literature reveals that similar study on 3-methyl-2-butanone with IQBC is still lacking. Hence prompted me to take up task for foregoing study.

\section{EXPERIMENTAL}

All the reagents and solvents used during the investigation are commercially available either B.D.H., E-Merck or S-Merck of extra pure quality except where specifically mentioned. The IQBC was prepared by dissolving weighed quantity of Chromium trioxide followed by addition of hydrobromic acid and Isoquinoline for a specific time period. The purity of crystals was confirmed by spectral method. The solution of the substrate was prepared in purified glacial acetic acid as required. The stock solutions of other reagents were prepared by usual recommended methods. The solutions were kept in a reaction vessels maintained at constant temperature $308 \mathrm{~K}$, in a equilibrated thermostatic bath. The progress of the kinetic reaction was monitored by withdrawing aliquots at definite intervals of time for the unconsumed IQBC iodometrically. The duplicate kinetic runs show reproducible results of rate constant within $\pm 3 \%$. The rate constants were evaluated by integration method.

\section{RESULTS AND DISCUSSION}

The kinetic measurement was performed under pseudo first-order condition by keeping [substrate] >> [oxidant]. The investigation indicated first-order dependency of rate with respect to [IQBC], which is 
further evidenced by linear plots of $\log (\mathrm{a}-\mathrm{x})$ vs. time with unit slope. The order varies from 1 to 0 for substrate at higher concentration which shows the existence of complex mechanism between reacting species of oxidant and enolic from of substrate (Table 1). The double reciprocal plot made between $\mathrm{k}^{-1}$ vs. [substrate] ${ }^{-1}$ is linear with positive intercept on Y-axis (Fig. 1). The study reveals that at higher concentration, it tends towards $\mathrm{X}$-axis showing limiting value of rate. It is evident that the rate of oxidation of substrate under probe increases with rising concentration of $\mathrm{H}^{+}$ions. The unit slope of plot $\log \mathrm{k}$ Vs. $\log \left[\mathrm{H}^{+}\right]$indicates that it obeys first-order kinetics with respect to $\mathrm{H}^{+}$ions and shows that reaction is acid catalysed.

It was observed that the reaction velocity of substrate increases with rise in the percentage composition of acetic acid constant in the reaction mixture (Table 2). The linear plot of log k vs. 1/D with positive slop is the evidence of this effect.

The study completely rules out the existence of free radicals based mechanism. They addition of foreign catalysts $\mathrm{CuSO}_{4}$ indicates an increase in rate whereas $\mathrm{MnSO}_{4}$ shows decreasing trend in rate of reaction. The rate of reaction is unaffected by added primary salts. This indicates that rate determining steps involves either neutral species or anion and a neutral, molecule. The observed stoichiometric measurement showed mole ratio 1:1 for IQBC and 3-methyl-2 butanone under study. The 3-methyl-2-oxobutanal was isolated as the oxidation product of the reaction, which is characterized by formation of 2:4 dinitrophyenyl hydrazines (M.P. $168^{\circ} \mathrm{C}$ ).

\section{- Mechanism For 3-Methyl-2-Butanone}

Considering the observed kinetic findings, a mechanism for an attack of reacting species $\mathrm{H}_{2} \mathrm{CrO}_{4}$ of oxidant IOBC at enolic substrate mav therefore be postulated in the slow process as:<smiles>C=C(O)C(C)C</smiles>

(keto)

(enol)

$$
\varnothing \mathrm{HCrO}_{3} \mathrm{Br}+\mathrm{H}_{2} \mathrm{O} \stackrel{\mathrm{K}_{1} \supset}{\rightleftharpoons} \mathrm{H}_{2} \mathrm{CrO}_{4}+\emptyset+\mathrm{HBr}
$$

(IQBC)

$$
\text { where } \varnothing=
$$
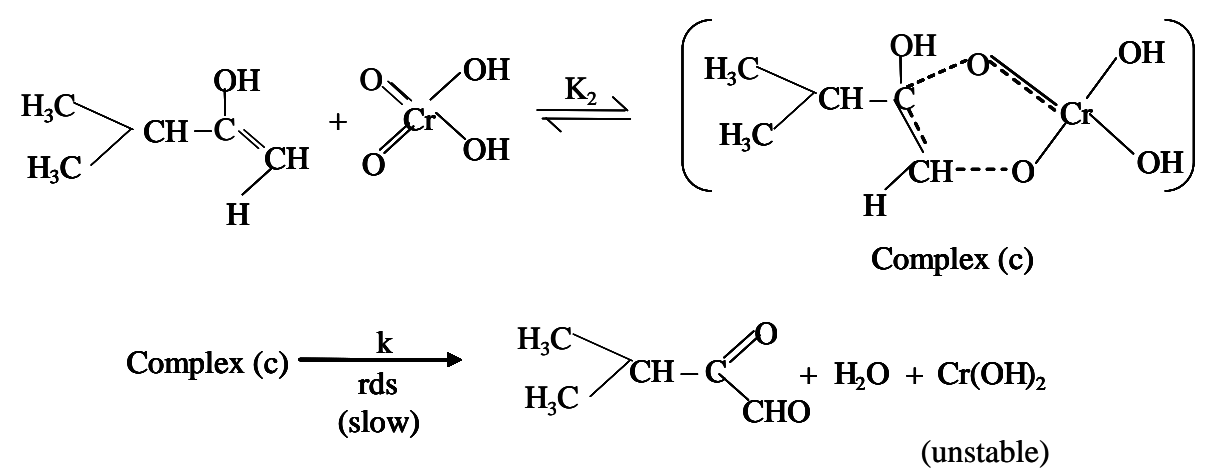

Applying steady state condition with reasonable approximation the mechanism leads to the following rate law: 


$$
\mathrm{k}_{\mathrm{obs}}=\frac{\mathrm{K}_{1} \mathrm{~K}_{2} \mathrm{k}[\mathrm{E}][\mathrm{H}+]}{[\mathrm{IQ}] \mathrm{K}_{1}+\mathrm{K}_{1} \mathrm{~K}_{2}[\mathrm{E}]}
$$

The formulated mechanism is also supported by the moderate value of energy of activation and other thermodynamic activation parameters. The validity of rate law was tested by making some assumptions. The intercept on $\mathrm{Y}$-axis of double reciprocal plot drawn between $1 / \mathrm{k}_{\mathrm{obs}} \mathrm{Vs}$. 1/[substrate] explains clearly the first to fractional-order as illustrated in complex mechanism of the reaction.

Table1. Effect of variation of [3-methyl-2-butanone] on reaction rate

$[\mathrm{IQBC}]=2.50 \times 10^{-3}\left(\mathrm{~mol} \mathrm{dm}^{3}\right)$;

$\left[\mathrm{H}^{+}\right]=1.0 \times 10^{-3}\left(\mathrm{~mol} \mathrm{dm}^{3}\right)$;

$\mathrm{HOAc}-\mathrm{H}_{2} \mathrm{O}=20 \%,(\mathrm{~V} / \mathrm{V})$;

Temperature $\mathrm{K}=308 \mathrm{~K}$

\begin{tabular}{|c|c|c|}
\hline Sr. No. & [3-methyl-2- butanone] $\mathbf{\times 1 0 ^ { 2 }}\left(\mathbf{m o l ~ d m}^{-\mathbf{3}}\right)$ & $\mathbf{1 0}^{\mathbf{4}} \mathbf{k}_{\mathbf{1}}\left(\mathbf{s}^{\mathbf{- 1}}\right)$ \\
\hline 1. & 1.25 & 1.16 \\
\hline 2. & 2.00 & 1.63 \\
\hline 3. & 2.50 & 1.79 \\
\hline 4. & 3.33 & 2.46 \\
\hline 5. & 4.00 & 2.65 \\
\hline 6. & 5.00 & 2.87 \\
\hline
\end{tabular}

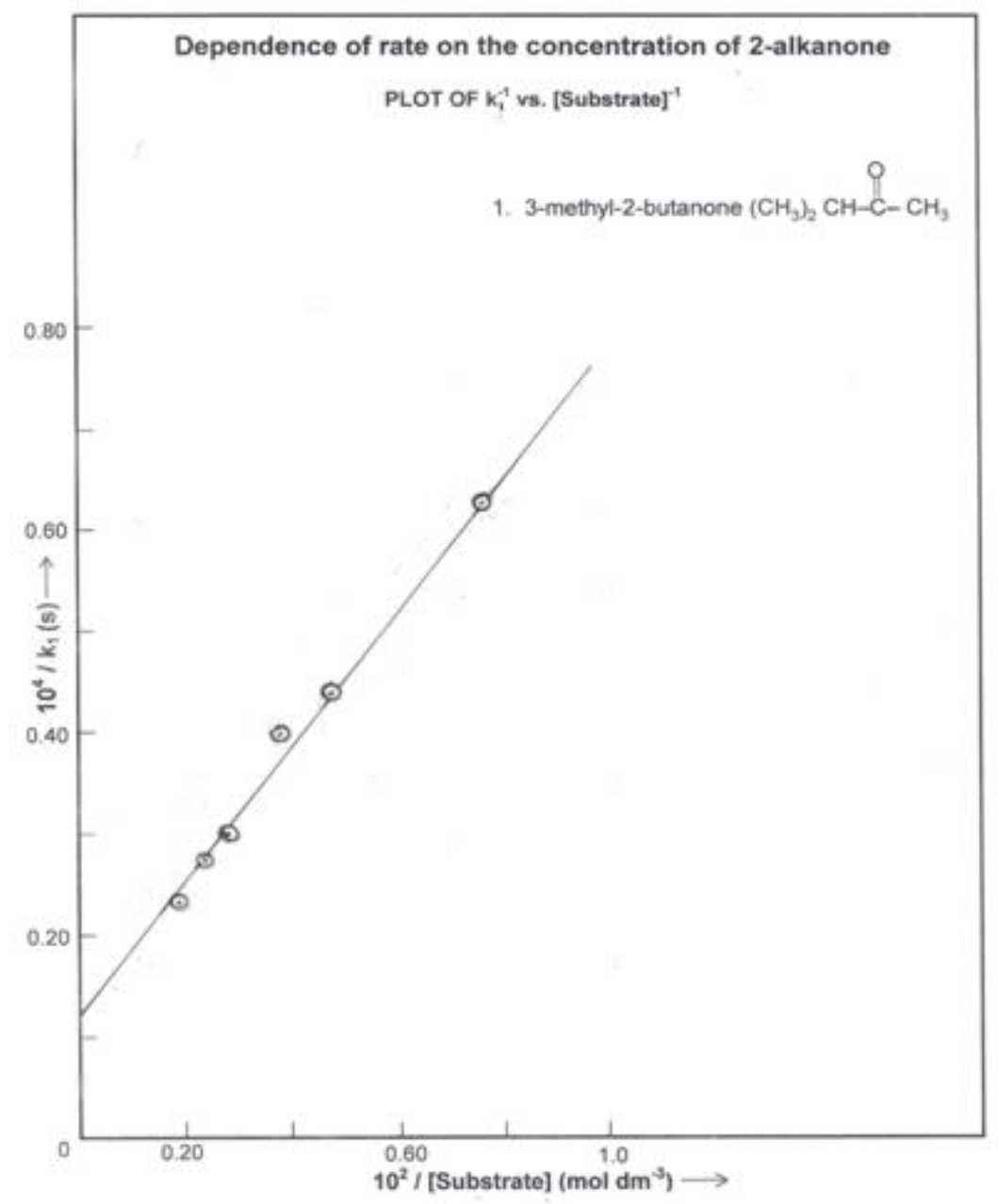

Fig1. $[I Q B C]=2.50 \times 10^{-3}\left(\mathrm{~mol} \mathrm{dm}^{3}\right) ;\left[\mathrm{H}^{+}\right]=1.0 \times 10^{-3}\left(\mathrm{~mol} \mathrm{dm}^{3}\right) ; \mathrm{HOAc}-\mathrm{H}_{2} \mathrm{O}=20 \%$, $(\mathrm{V} / \mathrm{V})$; Temperature $\mathrm{K}$ $=308 \mathrm{~K}$ 
Table2. Dependence of rate on Dielectric constant of the medium

[3-methyl-2- butanone] $=2.50 \times 10^{-2}\left(\mathrm{~mol} \mathrm{dm}^{3}\right)$;

$[\mathrm{IQBC}]=2.50 \times 10^{-3}\left(\mathrm{~mol} \mathrm{dm}^{3}\right)$;

$\left[\mathrm{H}^{+}\right]=1.0 \times 10^{-3}\left(\mathrm{~mol} \mathrm{dm}^{3}\right)$;

Temperature $=308 \mathrm{~K}$

\begin{tabular}{|c|c|c|c|}
\hline Sr. No. & HOAc-H $-H_{2} \mathbf{O}(\mathbf{v} / \mathbf{v})$ & $\frac{\mathbf{1 0}^{\mathbf{3}}}{\mathbf{D}^{*}}$ & $\mathbf{k}_{\mathbf{1}} \times \mathbf{1 0}^{\mathbf{4}}\left(\mathbf{s}^{\mathbf{- 1}}\right)$ \\
\hline 1. & 10 & 15.50 & 1.52 \\
\hline 2. & 20 & 17.17 & 1.79 \\
\hline 3. & 30 & 19.15 & 2.25 \\
\hline 4. & 40 & 21.98 & 2.71 \\
\hline
\end{tabular}

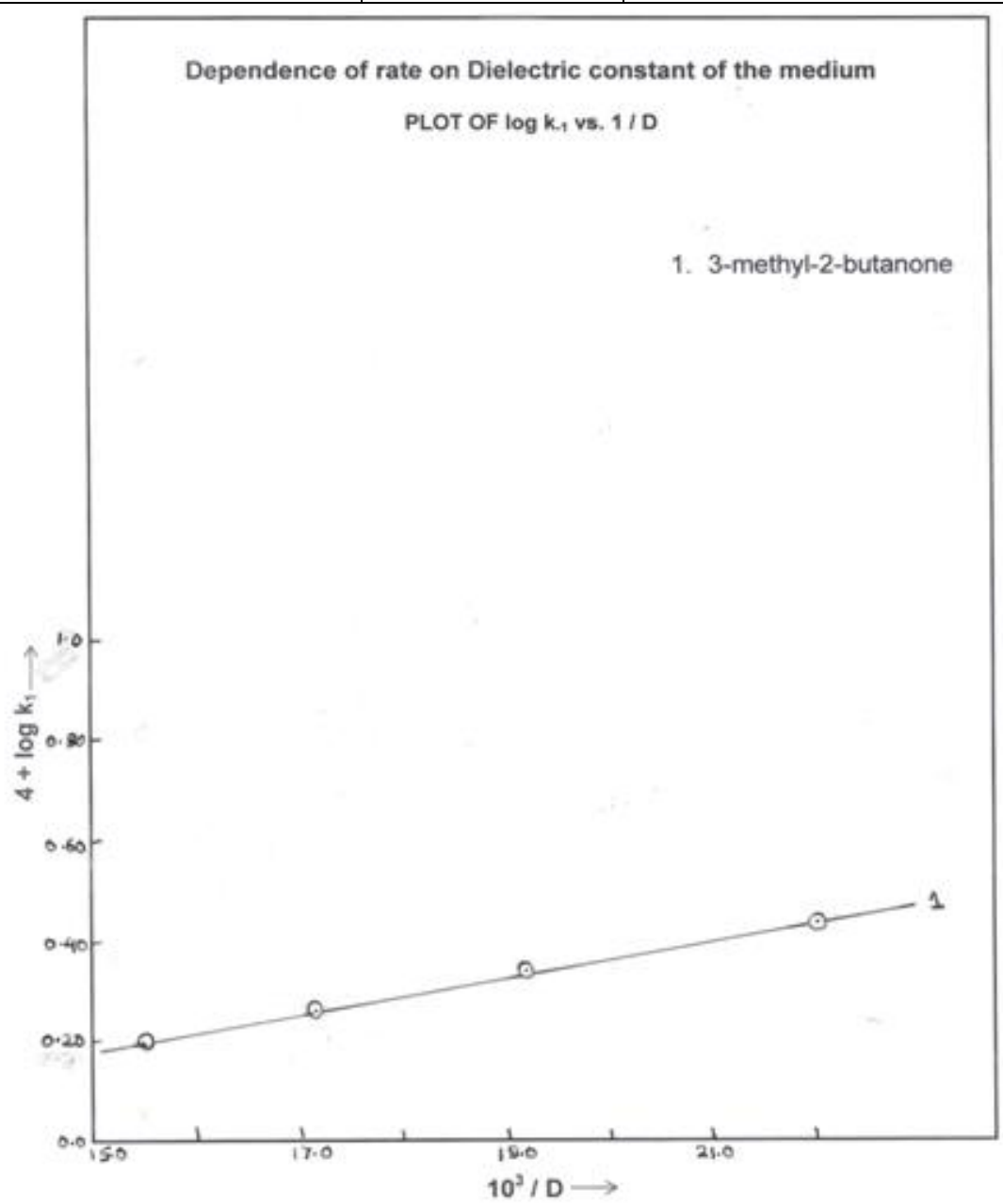

Fig2. $[$ Substrate $]=2.0 \times 10^{-2}\left(\mathrm{~mol} \mathrm{dm^{-3 }}\right) ;[I Q B C]=2.50 \times 10^{-3}\left(\mathrm{~mol} \mathrm{dm} \mathrm{m}^{3}\right) ;\left[\mathrm{H}^{+}\right]=1.0 \times 10^{-3}\left(\mathrm{~mol} \mathrm{dm}^{3}\right) ;$ Temperature $=308 \mathrm{~K}$

\section{CONCLUSION}

IQBC is a mild efficient economically cheap reagent containing $\mathrm{Cr}(\mathrm{VI})$ is able to work as both and oxidizing and Brominating agent. The mechanism of oxidation was explained through the formation of reacting species $\mathrm{H}_{2} \mathrm{CrO}_{4}$ and enol form of ketone precursor prior to rate rds altransition state. The validity of rate law was tasted by rate expression. The order of ketone changed from unity to a fraction at its higher concentration.

\section{REFERENCES}

[1] Tiwari, S., Khan, M.U., Tiwari,B.M.L., Tiwari, K.S., and Valechha, N.D., Oxid. Commun, 1999, 22(3), 416-423.

[2] Mohan, K.V., Raghunatha Rao, P., and Sundaram, E.V., J. Indian Chem. Soc., 1984, 61, 225. 
[3] Krishana Murti, M., Sanjeeva Raddy, C.H., and Sundaram, E.V., J. Indian Chem. Soc., 1989, $28(A), 2$.

[4] Manibala, H.S., Singh, B., Krishana, and Sundaram, E.V., J. Indian Chem. Soc., 1985, (62), 434.

[5] Palaniappan, A.N., Vaideki, S., Shrinivasan, S., and Ray, C. J. Chem. Pharm. Res., 2012, 4(1), 640-647.

[6] Vellaisamy, M., Suryakala, K., and Ravishankar, M., J. Chem. Pharm. Res., 2011, 3(5), 678-681.

[7] Karunakaran, C., and Chidambaranathan, V., Croat. Chem. Acta., 2001, 74(1), 5

[8] Dharma, Raja, J. Krishnasamy, K., and Shanmugam, M., E.J. Chem., 2008, 5, 754.

[9] Trivedi, Khushboo and Khan, M.U., E.J. Adv. Research, 2017, 3(2) , 113

[10] Anary-Abbasinejad, Mohammad, Charkhati, Khadije, and Hassanabadi, Alireza, J. Chem. Research, 2009, 2, 95-97.

[11] Khansole, S.V., and Vibhute, Y.B., Chinese Chemical Letters, 2009, Vol.20, Issue 3: 256-260.

Citation: K. Trivedi et al., "Kinetic and Mechanistic Study of Oxidation of 3-Methyl-2-Butanone by Isoquinolinium Bromochromate", International Journal of Advanced Research in Chemical Science (IJARCS), vol. 5, no. 1, pp. 4-8, 2018. http://dx.doi.org/10.20431/2349-0403.0501002

Copyright: (C) 2018 Authors. This is an open-access article distributed under the terms of the Creative Commons Attribution License, which permits unrestricted use, distribution, and reproduction in any medium, provided the original author and source are credited. 